\title{
Mars Atmosphere Resource Verification INsitu (MARVIN) - In Situ Resource Demonstration for the Mars 2020 Mission
}

\author{
Gerald B. Sanders ${ }^{1}$, Koorosh Araghi ${ }^{2}$, and Kim M. Ess ${ }^{3}$ \\ NASA Johnson Space Center, Houston, TX, 77058, USA \\ Lisa M. Valencia ${ }^{4}$, Dr. Anthony C. Muscatello ${ }^{5}$, and Dr. Carlos I. Calle ${ }^{6}$ \\ NASA Kennedy Space Center, FL, 32899, USA \\ Larry Clark ${ }^{7}$ \\ Lockheed Martin Space Systems Corporation, Littleton, CO, 80127, USA \\ and \\ Dr. Christie Iacomini ${ }^{8}$ \\ Paragon Space Development Corporation, Tucson, AZ, 85714, USA
}

\begin{abstract}
The making of oxygen from resources in the Martian atmosphere, known as In Situ Resource Utilization (ISRU), has the potential to provide substantial benefits for future robotic and human exploration. In particular, the ability to produce oxygen on Mars for use in propulsion, life support, and power systems can provide significant mission benefits such as a reducing launch mass, lander size, and mission and crew risk. To advance ISRU for possible incorporation into future human missions to Mars, NASA proposed including an ISRU instrument on the Mars 2020 rover mission, through an announcement of opportunity (AO). The purpose of the the Mars Atmosphere Resource Verification INsitu or (MARVIN) instrument is to provide the first demonstration on Mars of oxygen production from acquired and stored Martian atmospheric carbon dioxide, as well as take measurements of atmospheric pressure and temperature, and of suspended dust particle sizes and amounts entrained in collected atmosphere gases at different times of the Mars day and year. The hardware performance and environmental data obtained will be critical for future ISRU systems that will reduce the mass of propellants and other consumables launched from Earth for robotic and human exploration, for better understanding of Mars dust and mitigation techniques to improve crew safety, and to help further define Mars global circulation models and better understand the regional atmospheric dynamics on Mars. The technologies selected for MARVIN are also scalable for future robotic sample return and human missions to Mars using ISRU.
\end{abstract}

\section{Introduction}

The production of oxygen from the Martian atmosphere for use as a propellant or life-support consumable, known as In Situ Resource Utilization (ISRU), has the potential to provide substantial benefits for future robotic and human exploration such as a reduction in mass launched from Earth, reduced vehicle size, and reduced mission and crew risk. NASA mission studies, such as NASA's Mars Design Reference Missions (DRMs) and Architecture (DRA) $5.0^{1}$, have shown that in situ oxygen $\left(\mathrm{O}_{2}\right)$ production from carbon dioxide $\left(\mathrm{CO}_{2}\right)$ in the Mars atmosphere can result in a $60 \%$ reduction in landed mass for human Mars missions, and reduces the mass of the lander by over 25 metric tons compared to bringing propellant from Earth.

Before any enabling capability is incorporated into an actual human space mission, it must be adequately demonstrated at mission durations, environmental conditions, and operations applicable to the mission. For ISRU systems on Mars missions, potential risks include dust contamination, loss of efficiency, and contamination by trace

${ }^{1}$ ISRU Chief Engineer, NASA/JSC, EP3, and AIAA Member.

${ }^{2}$ Energy Storage Technology Manager, NASA/JSC, EP3, and AIAA Member Senior Member.

${ }^{3}$ Deputy for Resource Prospector Lander, NASA/JSC, EA3, and AIAA nonmember.

${ }^{4}$ Project Manager, NASA/KSC, EXE, and AIAA Member.

${ }^{5}$ Senior Chemist, NASA/KSC, NE-S-2, and AIAA nonmember.

${ }_{7}^{6}$ Manager, Electrostatics and Surface Physics Laboratory, NASA/KSC, NE-S, and AIAA nonmember..

${ }^{7}$ Program Manager, LMSSC, and AIAA Senior Member.

${ }^{8}$ Senior Aerospec Engineer, 3481 E. Michigan Street, and AIAA Senior Member. 
gases in the Martian atmosphere. Given the significance of ISRU for the human exploration of Mars, it is important to understand these potential problems as early as possible. One way to reduce the risk of incorporating ISRU propellant production into human Mars exploration is to perform a robotic mission that involves demonstrating all of the critical technologies and operations at a relevant scale associated with making propellants from in situ resources, storing them, and then using them in a propulsive application, such as launching from the Martian surface to return a sample to Earth. Since this robotic mission would be a critical step in the human exploration of the Mars surface, performing an ISRU precursor mission specifically aimed at demonstrating critical technologies and subsystems that may be affected by the environment on Mars would help ensure the success of this critical mission. Figure 1 below depicts the time phasing of these notional ISRU risk reduction missions with the goal of sending humans to Mars in the mid to late $2030 \mathrm{~s}^{2}$.

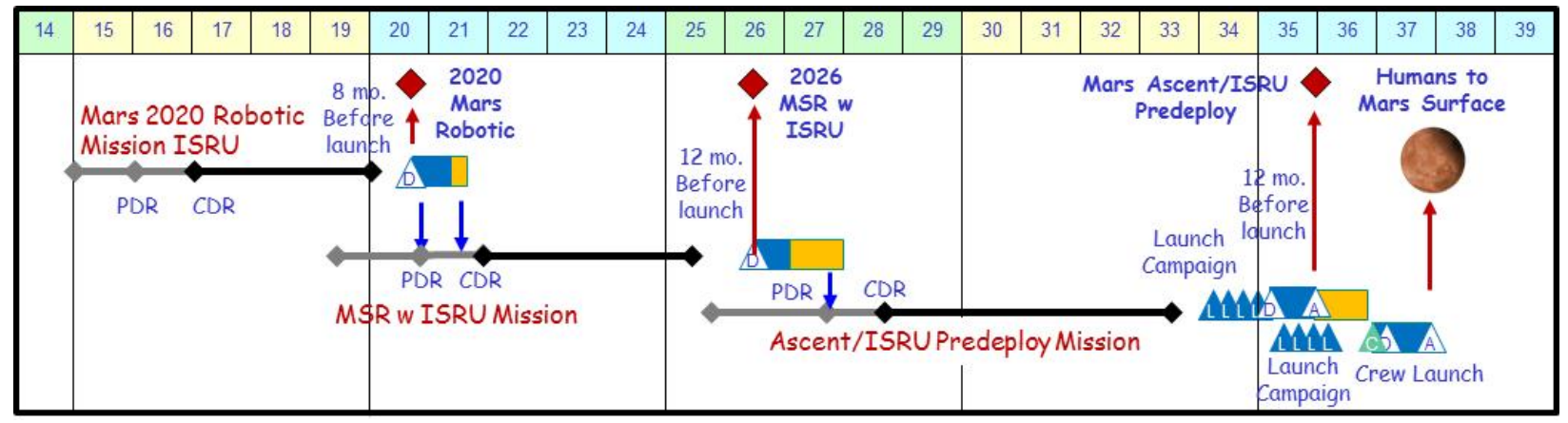

Figure 1. Notional ISRU Mission Phasing for Human Mars Exploration

\section{Mars ISRU Demonstration Opportunity}

To advance ISRU for possible incorporation into future human missions to Mars, NASA proposed including an ISRU demonstration instrument on the Mars 2020 rover mission, through an announcement of opportunity (AO). Because the mass, power, and volume associated with payloads on the Mars 2020 rover is very limited, the AO listed only two primary requirements for the ISRU demonstration instrument. The first primary requirement stated that the ISRU instrument was to process the Martian atmosphere to produce oxygen, store and measure the purity of the oxygen produced, operate intermittently during the rover's mission, and not interfere with the operations of the science instruments on the rover. Additional optional measurement goals for measuring the size distribution of dust particles ingested in the inlet stream of the ISRU instrument, and for measuring the temperature, pressure, and relative humidity of the inlet stream were also of interest to NASA if the mass, power, and volume allocated for the ISRU instrument were not exceeded. The second primary requirement stated that the ISRU demonstration instrument must produce oxygen at a minimum rate of $0.02 \mathrm{~kg} / \mathrm{hr}$ and operate a minimum of 50 sols on Mars. The Mars 2020 Landed Science Payload Proposal Information Package (PIP) associated with the AO also provided information on the allowable mass, power, volume, thermal interface with the rover, and mission/Mars environmental conditions. The maximum mass allowed for internal payloads was defined as $15 \mathrm{~kg}$, and the maximum volume was $23.9 \mathrm{~cm}$ x $23.9 \mathrm{~cm}$, x $30.8 \mathrm{~cm}\left(9.45^{\prime}\right.$ × 9.45' x 12.2'). Even with all of these payload limitations, the AO stated that it was highly desirable that the ISRU instrument demonstrate extensibility to capabilities for subscale validation $\left(0.44 \mathrm{~kg} / \mathrm{hr} \mathrm{O}_{2}\right)$ and future human mission needs $(2.2 \mathrm{~kg} / \mathrm{hr} \mathrm{O}$ ). The AO also specified that the Technology Readiness Level (TRL) for the technologies included in the ISRU demonstration instrument needed to be at TRL 6 by the Preliminary Design Review (PDR) 15 months after Authority to Proceed (ATP).

\section{MARVIN Purpose, Goals, and Objectives.}

In response to the AO for the ISRU demonstration on the Mars 2020 rover, the NASA Johnson Space Center (JSC) led a team of experts from NASA Kennedy Space Center and Goddard Space Flight Center and industry (Lockheed Martin Space Systems, Paragon Space Development Corporation, and Jacobs) to propose an instrument that would fulfill the three highest Strategic Knowledge Gaps (SKGs) identified by the Precursor Strategy Analysis Group (P-SAG): 1) Demonstrate technologies to enable propellant and consumable oxygen production from the Mars atmosphere, 2) Characterize atmospheric dust size and morphology to understand the effects on the operation of surface systems and human health, and 3) Collect surface weather measurements to validate global atmospheric models $^{3}$. Called the Mars Atmosphere Resource Verification INsitu or MARVIN, the instrument will provide the 
first demonstration of $\mathrm{O}_{2}$ production from Martian atmospheric $\mathrm{CO}_{2}$, and will also make environmental measurements that are critical to help further define Mars global circulation models (GCM) as well as better understand the regional atmospheric dynamics. The goals and objectives for the MARVIN ISRU investigation are listed in Table 1.

Table 1. MARVIN Instrument Goals and Objectives

\begin{tabular}{|c|c|}
\hline SKGs /MARVIN Instrument Goals & MARVIN Instrument Objectives \\
\hline $\begin{array}{l}\text { 1. Demonstrate technologies to enable propellant } \\
\text { and consumable oxygen production from the } \\
\text { Mars atmosphere for future exploration } \\
\text { missions }\end{array}$ & $\begin{array}{l}\text { a. Make oxygen }\left(\mathrm{O}_{2}\right) \text { from the carbon dioxide }\left(\mathrm{CO}_{2}\right) \text { in the Mars atmosphere at a } \\
\text { production rate of } 0.02 \mathrm{~kg} / \mathrm{hr} \\
\text { b. Measure the purity of the oxygen produced } \\
\text { c. Separate } \mathrm{CO}_{2} \text { from the Mars atmosphere and deliver } \mathrm{CO}_{2} \text { at the pressure and flow } \\
\text { rate needed to sustain oxygen production } \\
\text { d. Select, develop, and test technologies and subsystems that can be scaled up for use } \\
\text { in future missions involving propulsion, life support and/or regenerative fuel cell } \\
\text { power system applications }\end{array}$ \\
\hline $\begin{array}{l}\text { 2. Characterize atmospheric dust size and } \\
\text { morphology to understand the effects on the } \\
\text { operation of surface systems and human health }\end{array}$ & $\begin{array}{l}\text { a. Measure dust size/amount suspended in the Mars atmosphere before filtration } \\
\text { b. Evaluate suspended dust electrostatic properties based on electrostatic precipitator } \\
\text { effectiveness }\end{array}$ \\
\hline $\begin{array}{l}\text { 3. Collect surface weather measurements to } \\
\text { validate global atmospheric models }\end{array}$ & $\begin{array}{l}\text { a. Measure Mars atmosphere gas temperature and pressure } \\
\text { b. Operate atmosphere dust, temperature, and pressure measurement instruments } \\
\text { simultaneously with other weather instruments on the Mars } 2020 \text { rover. }\end{array}$ \\
\hline
\end{tabular}

Besides addressing the top three P-SAG SKGs, the MARVIN instrument will also address the Mars Exploration Program Analysis Group (MEPAG) Goal IV objectives ${ }^{4}$ that were divided into three categories: Architecture Drivers, Crew Safety, and Operational. For Architecture Drivers, the MARVIN instrument will demonstrate ISRU technologies and take measurements of the Mars environment that will provide critical data for subsequent designs to reduce the mass of propellants and other consumables launched from Earth. For Crew Safety, the MARVIN instrument will take measurements of suspended dust particle size and amount entrained during atmosphere collection at different times of the Mars day and year critical to understanding the risk of dust inhalation by the crew. For Operational, the MARVIN instrument will provide critical data on performance degradation due to long term exposure of Mars dust on instruments, seals, and reactive surfaces, and may provide critical data on suspended dust electrostatic properties through operation of an electrostatic precipitator for dust filtration.

\section{MARVIN Instrument Description}

To perform the investigations required to address the three primary mission goals and objectives in Table 1, the MARVIN instrument will incorporate three subsystems to measure the atmosphere, separate carbon dioxide $\left(\mathrm{CO}_{2}\right)$ from the Mars atmosphere, pressurize the $\mathrm{CO}_{2}$, and make oxygen $\left(\mathrm{O}_{2}\right)$. These subsystems are described in Table 2 with graphics of the hardware associated with their operation. While design requirements for each MARVIN subsystem will be presented in detail in the following subsections, Table 3 depicts the top-level performance requirements for the MARVIN instrument.

Based on numerous studies, including the Mars DRA $5.0 \mathrm{study}^{5-17}$, that have examined ISRU technology and process options for collecting and separating $\mathrm{CO}_{2}$ from other constituents in the Mars atmosphere, providing the purified $\mathrm{CO}_{2}$ at elevated pressures ( $\geq 150: 1$ compression ratio), and processing techniques for converting $\mathrm{CO}_{2}$ into $\mathrm{O}_{2}$ and other mission consumables, the MARVIN team selected two critical ISRU technologies for the collection and separation of $\mathrm{CO}_{2}$ from the Mars atmosphere, and conversion of $\mathrm{CO}_{2}$ into $\mathrm{O}_{2}: \mathrm{CO}_{2}$ Freezing/Heating and Solid Oxide Electrolysis (SOE).

Because the MARVIN instrument is just one of several payloads on the Mars 2020 rover, it must interface with the rover's computer/software for start and stop operation commands and data transfer, the thermal interface plate for thermal management and heat rejection, and the power system to obtain power for MARVIN operations. Figure 2 provides a simplified fluid schematic of the three main MARVIN subysystems, and depicts the interfaces between MARVIN subsystems and their interfaces with critical rover subsystems. 
Table 2. MARVIN Instrument Subsystems

Atmosphere and Dust Measurement and Filtration
(ADMF)
Measures pressure, temperature, and suspended dust
particle size and amount entrained in atmosphere
gases. Filter and pump gases to ICE CUBE.

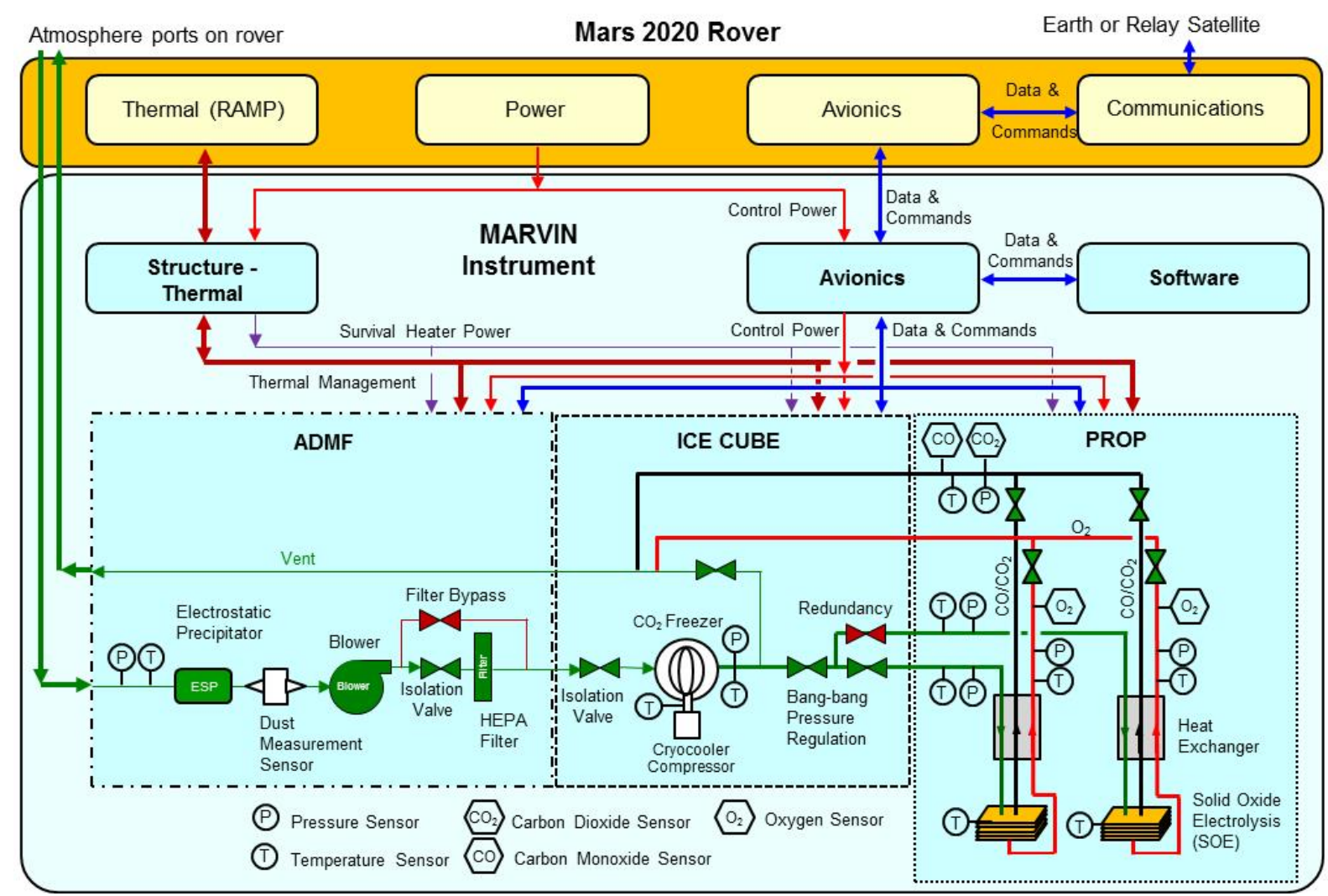

Figure 2 MARVIN Functional Block Diagram and Simplified Fluid Schematic 
Table 3. MARVIN Top-Level Performance Requirements

\begin{tabular}{|c|c|c|}
\hline Design Parameter & \multicolumn{2}{|c|}{ Performance Requirement } \\
\hline \multirow{4}{*}{$\begin{array}{r}\text { Mars atmosphere collection - rate } \\
\text { dust particle size } \\
\text { filtration effectiveness } \\
\text { operations }\end{array}$} & \multicolumn{2}{|c|}{$3100 \mathrm{sccm}$ (standard cubic centimeters) } \\
\hline & 0.1 to 10 microns & \pm 0.05 microns accuracy \\
\hline & \multicolumn{2}{|c|}{$>99 \%$ particles larger than 0.3 microns } \\
\hline & \multicolumn{2}{|c|}{60 nominal } \\
\hline \multirow{2}{*}{$\mathrm{CO}_{2}$ collection from atm. - rate } & \multicolumn{2}{|c|}{$0.02 \mathrm{~kg} / \mathrm{hr}$ (kilograms/hour) } \\
\hline & 50 watts ave. & 60 watts peak \\
\hline \multirow{3}{*}{$\begin{array}{r}\text { Pressure (kilopascals - kPa) } \\
\text { temperature } \\
\text { operations }\end{array}$} & $0-4826 \mathrm{kPa}(0-700 \mathrm{psi})$ & $6895 \mathrm{kPa} \max (1000 \mathrm{psi})$ \\
\hline & \multicolumn{2}{|c|}{-123 to $+50^{\circ} \mathrm{C}\left(-189\right.$ to $\left.122^{\circ} \mathrm{F}\right)$} \\
\hline & \multicolumn{2}{|c|}{50 nominal } \\
\hline $\mathrm{O}_{2}$ production - $\mathrm{CO}_{2}$ feed rate & $1036 \mathrm{sccm}$ & $0.11 \mathrm{~kg} / \mathrm{hr}(3.9 \mathrm{oz} / \mathrm{hr})$ \\
\hline $\mathrm{O}_{2}$ production rate & $258 \mathrm{sccm}$ & $0.02 \mathrm{~kg} / \mathrm{hr}(0.7 \mathrm{oz} / \mathrm{hr})$ \\
\hline pressure & \multicolumn{2}{|c|}{90 to $103 \mathrm{kPa}(13-15 \mathrm{psi})$} \\
\hline temperature & \multicolumn{2}{|c|}{750 to $850^{\circ} \mathrm{C}\left(1382-1562^{\circ} \mathrm{F}\right)$} \\
\hline power & 120 watts ave. & 205 watts peak \\
\hline operations & \multicolumn{2}{|c|}{50 nominal } \\
\hline \multirow{2}{*}{$\begin{array}{r}\text { MARVIN Instrument - } \begin{array}{r}\text { Baseline } \\
\text { Threshold }\end{array} \\
\end{array}$} & $12.7 \mathrm{~kg}(19.7 \%)$ & $23.9 \times 23.9 \times 31.9 \mathrm{~cm}$ \\
\hline & \multicolumn{2}{|c|}{$9.1 \mathrm{~kg}(19.9 \%$ contingency $)$} \\
\hline
\end{tabular}

\section{A. Atmosphere and Dust Measurement and Filtration (ADMF) Subsystem}

The purpose of the (ADMF) subsystem is to collect raw atmospheric gas and dust from a port on the Mars 2020 rover, measure the local gas temperature, pressure, and dust concentration, remove a majority of the entrained dust, and deliver filtered or unfiltered atmosphere to the ICE CUBE subsystem. The NASA Kennedy Space Center (KSC) is responsible for the design, development, and delivery of the ADMF for integration into the MARVIN instrument.

The flow of the Mars atmosphere through the ADMF is driven by a blower. The nominal flow rate of atmospheric gas is 40 actual liters per minute or 3100 standard cubic centimeters per minute (sccm) during nominal operations and environmental conditions. The blower selected for the ADMF, a ROTON axial fan, will provide sufficient flow to overcome the flow resistance of the filter and the two valves in the ICE CUBE subsystem. Even though it is expected that the ROTRON blower will meet mission requirements, during Phase A a large selection of available miniature blowers will be examined, and during Phase B the ROTRON and possibly a second blower will be tested under Mars environmental conditions to ensure the blower achieves a TRL of 6 before the Preliminary Design Review (PDR). There is high confidence in the blower achieving TRL 6 since a centrifugal blower was tested to TRL 6 in the 1990s by Lockheed Martin under Mars environment conditions ${ }^{18}$.

The measurement of atmospheric gas temperature and pressure are important to the operations of the MARVIN instrument, and will also support scientific studies. These measurements will provide high resolution and rapidly responding data to capture changes in the weather. The expected temperatures in the Mars atmosphere range from about $-128^{\circ} \mathrm{C}$ to $+50^{\circ} \mathrm{C}$ while pressures vary from a few hundred Pascal to 1.3 kilopascal $(\mathrm{kPa})$. The environmental measurement sensors are located just inside the atmosphere inlet port in the instrument. The sensors will be positioned such that measurements will remain valid with or without blower-induced flow, and will be shielded from ambient wind, ground and sky heat radiance, and isolated from payload induced thermal effects. The ADMF subsystem can operate alone or in conjunction with other rover instruments. Temperature and pressure measurements will utilize flight quality sensors based on models the team has used previously.

The purpose of the filter in the ADMF subsystem is to absorb a large fraction of the inlet particles. The filtration system in the ADMF subsystem will remove over $99 \%$ of the suspended dust larger than 0.3 microns. To evaluate the impact of dust exposure on MARVIN components, a filter bypass line will be included in the ADMF subsystem to allow unfiltered atmosphere collection and processing after baseline mission objectives have been met. The ADMF subsystem will incorporate an electrostatic high-efficiency particulate absorption (HEPA) filter that can be back-flushed using high pressure $\mathrm{CO}_{2}$ to evaluate filter cleaning effectiveness. The ADMF team has successfully developed an electrostatic precipitator (ESP) modified to sustain a charging corona and collection electric field for the Martian environment ${ }^{19-22}$. Extensive experiments on the ESP concept in a partially simulated Martian atmosphere $\left(\mathrm{CO}_{2}\right.$ at $\left.0.8 \mathrm{kPa}\right)$ with Martian simulant dust particles (with diameters $<10 \mu \mathrm{m}$ range) aerosolized inside the vacuum chamber demonstrated dust removal efficiencies up to $99 \%$. Therefore, a technology development effort will be pursued before PDR to reduce the packaging of the KSC ESP filter concept (see Figure 3). If the ESP is approved for incorporation into the MARVIN ADMF subsystem at PDR, it will be installed either in the filter bypass line allowing for the evaluation of two dust filter concepts or before the Dust Measurement Sensor so that dust electrostatic properties can be evaluated. 


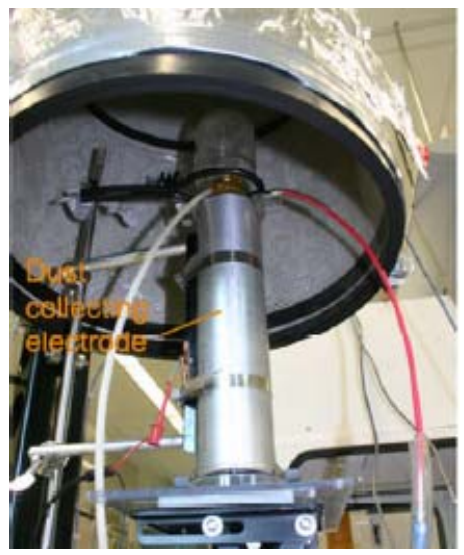

Figure 3. Electrostatic Precipitator Test Article at KSC

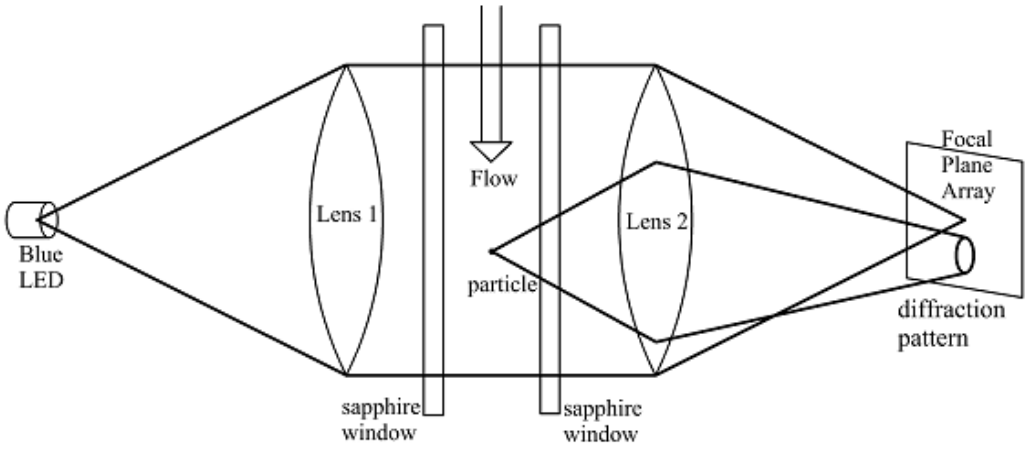

Figure 4. Dust Measurement Sensor Concept

The Dust Measurement Sensor (DMS) is based on commercially available sensors used in industry ${ }^{23-26}$. Immediately upon entering the ADMF, the atmosphere flow will pass between two closely spaced optical windows and a coherent blue light source, expanded to a parallel window-filling beam, will pass across the space and be imaged by a Charge Coupled Device (CCD) array beyond the second window (as depicted in Figure 4). The blue light will interact with any dust particles and will produce diffraction patterns on the CCD image (instead of crisp shadows). The dimensions of these patterns including spacing between light and dark fringes and the asymmetry will provide estimates of the particle sizes and shapes. Flow velocity can also be estimated with a rapid double exposure. The system will provide images of particles in the 0.5 to 10 micron range with an expected sizing error of \pm 0.05 microns. Calibration is accomplished with commercially available calibration particles. Dust counting will be performed by subtracting sequential images thereby mitigating the impact of dust adherence. This technique also subtracts out other optical artifacts.

\section{B. Integrated Cryogenic Extraction of $\mathrm{CO} 2$ and Utilization By Expansion (ICE CUBE)}

The purpose of the ICE CUBE subsystem is to separate $\mathrm{CO}_{2}$ from the Mars atmosphere at low Mars surface pressures, and provide pure $\mathrm{CO}_{2}$ to the Precursor Reactor for Oxygen Production (PROP) subsystem at the pressure and flow rate needed to produce $\mathrm{O}_{2}$ at $0.02 \mathrm{~kg} / \mathrm{hr}$ for one hour. The Lockheed Martin Space Systems Corporation (LMSSC) is responsible for the design, development, and delivery of the ICE CUBE subsystem for integration into the MARVIN instrument. When considering past studies of technologies associated with collecting, separating, and pressurizing $\mathrm{CO}_{2}$ from the Mars atmosphere and the mass, power, and volume constraints of the ISRU instrument payload, the MARVIN team selected $\mathrm{CO}_{2}$ Freezing/Heating as the best option for meeting the MARVIN mission requirements. This technology provides combined power efficiency and durability with simplicity and mass efficiency making it the clear choice over either Dual-Stage Mechanical Compressors with Membrane Separation or Dual-Stage Rapid Cycle Adsorption which are the other two technologies considered for this task. Dual-Stage Mechanical Compressors with Membrane Separation, are power intensive, heavy, and have operating life duration concerns. Dual-Stage Rapid Cycle Adsorption requires a separate and complex thermal fluid control system for heating and cooling of the adsorption beds, the beds also can get contaminated by water, are sensitive to dust clogging, and the amount of $\mathrm{CO}_{2}$ collected is directly proportional to the sorbent mass, so larger scale systems will be heavier ${ }^{27}$.

Using $\mathrm{CO}_{2}$ freezing/heating technology already demonstrated in the laboratory under simulated Mars surface conditions, the ICE CUBE subsystem will operate in two modes during the mission: $\mathrm{CO}_{2}$ Collection mode and Pressurized $\mathrm{CO}_{2}$ Delivery mode. In the $\mathrm{CO}_{2}$ Collection mode, the ICE CUBE subsystem is designed to accept filtered or unfiltered Martian atmosphere, freeze $\mathrm{CO}_{2}$ on a cold head chilled to $-123.15^{\circ} \mathrm{C}(150 \mathrm{~K})$, the triple point of $\mathrm{CO}_{2}$ at Mars atmospheric pressure, and reject nitrogen, argon, and other minor components from the atmosphere except for the small amount of water vapor present. Under nominal conditions of $0^{\circ} \mathrm{C}$ at the instrument-to-rover thermal interface (the Rover Avionics Mounting Plate or RAMP) and a Mars atmospheric temperature of $210 \mathrm{~K}$ $\left(-63^{\circ} \mathrm{C}\right)$, the cryocooler will provide 4 watts (W) of cooling with $40 \mathrm{~W}$ of power. Assuming a $\geq 50 \% \mathrm{CO}_{2}$ capture rate based on similar systems, ICE CUBE will collect $\mathrm{CO}_{2}$ at a rate of $20 \mathrm{~g} / \mathrm{hr}$ for up to 8 hours $(0.160 \mathrm{~kg})$. The ICE CUBE subsystem will collect a total of 0.12 to $0.16 \mathrm{~kg}$ of $\mathrm{CO}_{2}$ per collection cycle. 
The ICE CUBE subsystem will use a miniature cryocooler to freeze $\mathrm{CO}_{2}$ onto a cold head/heat exchanger. This heat exchanger will incorporate lessons learned from past tests at LMSSC and recent improvements developed at NASA KSC during testing of the frozen $\mathrm{CO}_{2}$ concept for use at even larger collection rates for a small sample return mission propellant production plant ${ }^{16}$. The cryocooler weighs less than 300 grams, and is $7.62 \mathrm{~cm}$ long with a diameter of $2.54 \mathrm{~cm}$, giving it a small footprint. The micro-cryocooler has recently been tested to space qualification standards, including additional temperatures cycles specific to the Martian environment, and has successfully passed all vibration and thermal testing with no loss of performance (i.e. the cryocooler is TRL 6). Collection of $\mathrm{CO}_{2}$ from the Mars atmosphere is also at TRL 6 based on testing performed at LMSSC of a $\mathrm{CO}_{2}$ Freezer Unit in the late 1990s for requirements similar to MARVIN ${ }^{18}$. Testing also showed the rapid self-pressurization and high pressure delivery after the frozen $\mathrm{CO}_{2}$ melted in a closed container (Figure 5).
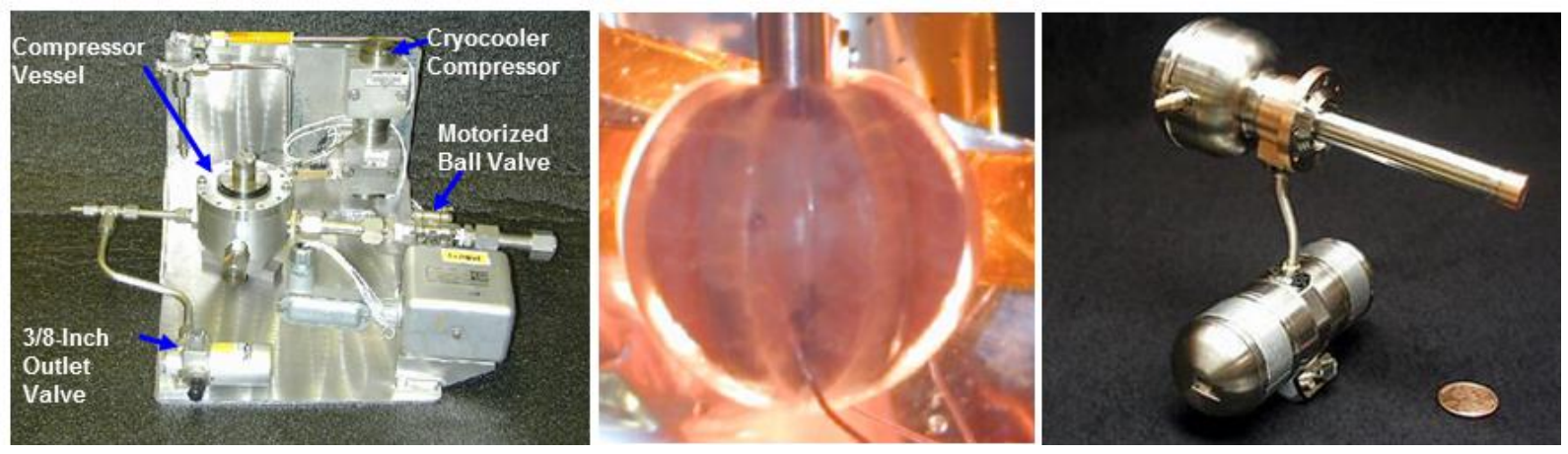

Figure 5. LMSSC CO 2 Freezer Unit (1); Frozen $\mathrm{CO}_{2} /$ Heat Exchange (c); Microcryocooler (r)

Key benefits of the ICE CUBE cryogenic $\mathrm{CO}_{2}$ collection/compression approach concept are i) the final product is pure high pressure $\mathrm{CO}_{2}$, ii) it greatly reduces the $\mathrm{CO}_{2}$ collection and pressurization subsystem and storage volume, and iii) it minimizes risks due to long-duration operation. Pressurized $\mathrm{CO}_{2}$ Delivery mode starts after collection of the $\mathrm{CO}_{2}$ is completed. The vessel surrounding the cold head is sealed with latching solenoid valves and the frozen $\mathrm{CO}_{2}$ is allowed to melt in order to self-pressurize in the vessel. This method leaves high pressure liquid $\mathrm{CO}_{2}$ in the storage tank, providing an effective compressions ratio of over 5000:1 with no additional mechanical devices. The MARVIN instrument is designed to be fail-safe operationally. The pressure vessel will be designed to ensure there will be no risk of damage to MARVIN, other science instruments, or the rover when pressurized.

\section{Precursor Reactor for Oxygen Production (PROP) Subsystem}

The purpose of the Precursor Reactor for Oxygen Production (PROP) subsystem is to produce $\mathrm{O}_{2}$ from $\mathrm{CO}_{2}$ on Mars at a production rate of $0.02 \mathrm{~kg} / \mathrm{hr}$. The NASA JSC is responsible for the design, development, and delivery of the PROP subsystem for integration into the MARVIN instrument with Solid Oxide Electrolysis-Embedded Sabatier Reactor (SOE-ESR) units and thermal/vibration isolation packaging provided by Paragon Space Development Corporation (Paragon). The use of SOE technology for conversion of $\mathrm{CO}_{2}$ into $\mathrm{O}_{2}$ allows for unlimited oxygen generation anywhere on Mars, and without reliance of Earth-supplied reactants or consumables. The oxygen produced is pure and can be immediately used for humans to breathe, as an oxidizer in fuel cell power, or for chemical propulsion ${ }^{28}$. From the large range of oxygen production options considered in Mars DRA 5.0 and subsequent Mars ISRU trade studies, the MARVIN team selected the SOE-ESR technology from Paragon since it can perform three different chemical processes with one piece of hardware:

1. it is the least complex process to extract $\mathrm{O}_{2}$ from $\mathrm{CO}_{2}$.

2. the same unit can be used to not only to electrolyze $\mathrm{CO}_{2}$ into $\mathrm{O}_{2}$, but also to electrolyze water $\left(\mathrm{H}_{2} \mathrm{O}\right)$ into $\mathrm{O}_{2}$ and hydrogen $\left(\mathrm{H}_{2}\right)$

3. it is unique in that it can perform Sabatier operations to make methane $\left(\mathrm{CH}_{4}\right)^{29}$.

There is no other comparable technology that can currently do this ${ }^{30-33}$. Because SOE-ESR technology uses a cell and stack approach similar to fuel cells, production operations are easily scalable to different production rates.

An SOE cell uses an electrolyte made of a nonporous ceramic oxide, such as yttria-stabilized zirconia (YSZ), which conducts oxygen ions at elevated temperatures $\left(750^{\circ} \mathrm{C}\right.$ to $\left.850^{\circ} \mathrm{C}\right)$. Electrically-conducting porous cathodes and anodes attached on opposite sides of the electrolyte facilitate gas/electron transport and act as catalysts. At the cathode, an oxygen atom is liberated from $\mathrm{CO}_{2}$, via an endothermic reaction. The oxygen atom receives two electrons from the cathode to become a doubly charged oxygen ion, $\mathrm{O}^{2-}$. A voltage applied to the electrodes drives 
the oxygen ion through vacancies in the crystal lattice of the nonporous electrolyte, and when the ion reaches the other side of the cell it releases the electrons to the anode and combines with another oxygen atom to form an $\mathrm{O}_{2}$ molecule. The voltage applied across the cells in the SOE stack in conjunction with the $\mathrm{CO}_{2}$ supply rate drive the $\mathrm{O}_{2}$ production rate. A SOE stack can also generate $\mathrm{O}_{2}$ from $\mathrm{H}_{2} \mathrm{O}$ vapor via the exact same process but instead of producing $\mathrm{CO}$, it produces $\mathrm{H}_{2}$ in the cathode exhaust. The overall process that occurs in the SOE stack is depicted in Figure 6. Besides electrolyzing $\mathrm{CO}_{2}$ and $\mathrm{H}_{2} \mathrm{O}$, with proper selection of the electrode catalyst, the $\mathrm{CO}$ and $\mathrm{H}_{2}$ byproducts can be converted into $\mathrm{CH}_{4}$ at a lower temperature. This reaction is performed in a second SOE-ESR stack in series with the first electrolysis stack.

\section{Cathode Reactions:}

$2 \mathrm{H}_{2} \mathrm{O}+4 \mathrm{e}^{-} \rightarrow 2 \mathrm{H}_{2}+2 \mathrm{O}^{2}$

$2 \mathrm{CO}_{2}+4 \mathrm{e}^{-} \rightarrow 2 \mathrm{CO}+2 \mathrm{O}^{2-}$

$\mathrm{O}_{2}+4 \mathrm{e}^{-} \rightarrow \mathrm{O}+2 \mathrm{O}^{2-}$

Anode Reactions: $2 \mathrm{O}^{2-} \rightarrow 4 \mathrm{e}^{-}+\mathrm{O}_{2}$

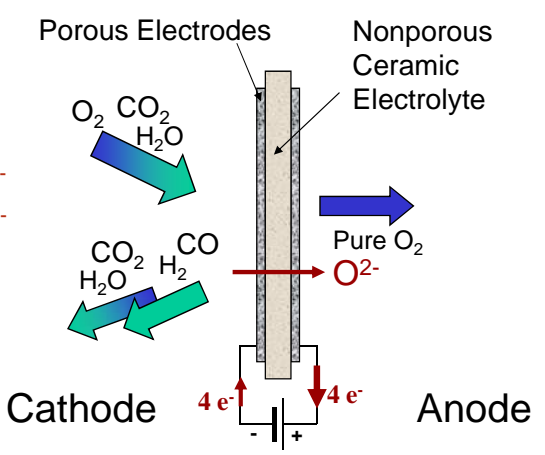

Figure 6. SOE Operation Illustration (single cell)

Due to the importance of demonstrating the production of oxygen on Mars, the PROP subsystem will contain two SOE-ESR units for redundancy. Because the impact of dust on ISRU hardware performance and hardware life is a driving factor in performing an early ISRU demonstration on Mars, having two SOE-ESR units can also enable a direct comparison of SOE performance with and without filtered atmosphere by using one unit with filtered $\mathrm{CO}_{2}$ and one with unfiltered $\mathrm{CO}_{2}$ through the bypass valve. If no degradation in performance is measured, future missions could incorporate simplified or no atmosphere dust filtering. This investigation would only be performed after baseline MARVIN mission objectives are fulfilled.

Oxygen production, as well as $\mathrm{O}_{2} / \mathrm{CH}_{4}$ production in a dual SOE-ESR stack arrangement, was demonstrated recently under NASA Small Business Innovation Research (SBIR) Phase I, II, and III contract ${ }^{34-35}$ with a dual unit depicted in Figure $71^{29-33}$. To produce oxygen at $0.02 \mathrm{~kg} / \mathrm{hr}$ requirement, the PROP SOE stack will operate at $850^{\circ} \mathrm{C}$, require $120 \mathrm{~W}$ of power, and incorporate 17 cells in the stack. The power for heater maintenance during $\mathrm{O}_{2}$ production will depend upon the insulation design surrounding the stack, and is initially calculated to be $70 \mathrm{~W}$. An insulation vs power trade will be performed in Phase A to optimize MARVIN mass, power, and volume. Each cell in the SOE stack includes an electrolyte and electrodes on both sides sandwiched between two metal manifolds of $\sim 5.6 \mathrm{~cm}$ diameter. The electrodes are screen-printed mixed electronic and ionic conductors (Figure $7 \mathrm{r}$ ). The internal rib pattern used to provide electrical contact between the manifold and electrode has been optimized to facilitate uniform gas coverage over the electrode. A simple "lobed" design provides for gas distribution and collection from multiple cells in the stack. Glass paste is used to isolate the cathode and anode $\left(\mathrm{O}_{2}\right)$ sides as well as prevent leaks. The same lobe concept is used to aid in cell alignment using alignment pins.

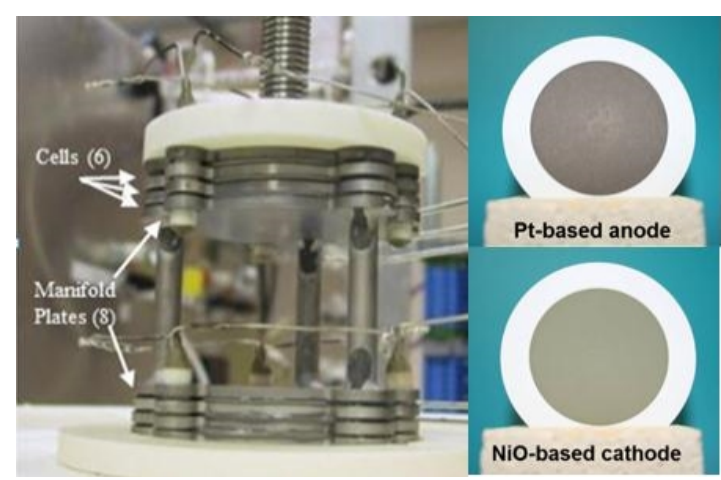

Figure 7. SOE-ESR Dual Stack (1); $10 \mathrm{~cm}^{2}$ electrodes on $8 \mathrm{YSZ}$ electrolyte (r)

The MARVIN SOE stack and packaging draws heritage from the single cell SOE unit designed, built, integrated, and flight certified under Mars environmental conditions and mission environments for the Mars In situ propellant production Precursor (MIP) flight experiment for the 2001 Mars Surveyor mission. The MIP SOE was $3.2 \mathrm{~cm}$ diameter with $3.14 \mathrm{~cm}^{2}$ electrode area and built by a team of scientists at the University of Arizona and JSC, reaching TRL of 8 before the mission was cancelled. 
During the SBIR Phase I, II, and III contracts with Paragon, a six-cell stack was designed, built, and tested at one-third the size of that required for MARVIN. The requirements on the six-cell SBIR stack were no pressure differential and only one-thermal cycle. For MARVIN mission requirements, to increase the stack design to TRL 6, the seals on the SOE stack will need to withstand over 50 thermal cycles and a differential pressure of $103.4 \mathrm{kPa}$ (15 psi). Paragon has identified several design concepts to meet the thermal cycle and differential pressure requirement. The two most promising concepts will be evaluated before PDR. The baseline seal approach leverages the existing Paragon seal design but with a newly developed glass that has a Coefficient of Thermal Expansion (CTE) better matched to the sealing surfaces. The vendor for the newly developed glass has demonstrated 100 thermal cycles from room temperature up to $850^{\circ} \mathrm{C}$ at 5 degrees $/ \mathrm{min}$. The second seal approach uses a viscous glass that bonds well with the metal manifold and YSZ materials. This glass seal is being used in solid oxide fuel cells at operating temperatures up to $850^{\circ} \mathrm{C}$. The vendor for the viscous glass has demonstrated 148 thermal cycles from room temperature up to $800^{\circ} \mathrm{C}$ and holding pressure differentials up to $103.4 \mathrm{kPa}$ (15 psi) for over 5 hours, all with no failures.

To heat and maintain the SOE stacks at operating temperature, the Paragon SOE stacks will use heater alignment pins developed during the SBIR contracts. The heater alignment pin minimizes mass and volume (since the pin doubles as a heater) and lowers energy consumed (due to thermal conduction vs. radiation in typical ovens). Since the heater alignment pins do not enclose the stack, they allow for greater flexibility in stack structural support, shock/vibration attenuation, and electrical and fluid connections. More corrosion-resistive heating elements will be investigated before PDR to ensure shelf life requirements are met.

For $\mathrm{O}_{2}$ content/purity measurement, a zirconia-oxide type of sensor was selected for the baseline design. The zirconia-oxide cell consists of a solid electrolyte made of zirconium oxide ceramic with surfaces exposed to the fluid environment and a reference environment. The material develops a potential difference between the surfaces that are exposed to the different environments. The zirconia-oxide type of sensor is capable of measuring 0 to $100 \%$ oxygen concentration in a pressure environment of $0.2 \mathrm{kPa}$ to $300 \mathrm{kPa}$ with an accuracy of $<0.5 \mathrm{kPa}$. They are used often in flowing gas measurements $(0-10 \mathrm{~m} / \mathrm{s})$, are robust, small, and readily available in industry [ref 36-38]. For CO and $\mathrm{CO}_{2}$ measurements, a variety of off-the-shelf infrared absorption and electrochemical technology based sensors are available. Infrared sensors are simple, rugged and reliable. Electrochemical sensors are accurate to $+/-2 \%$, are low cost, easy to install, and require little power.

\section{MARVIN Operation}

All payloads for the Mars 2020 rover need to be able to operate at any time of the Mars day and during any time in the Mars year. Because of the time delay between Earth and Mars, all MARVIN operations will need to be automated. The Mars 2020 PIP states that the heritage power/energy system for the Curiosity rover provides approximately 1000 watt-hours (W-hrs) per Mars day (sol) for all surface operations, and that the rover will provide between 100 and $600 \mathrm{~W}$-hrs per sol for payload operations with a voltage between 22 and 36 volts. Because of the limited energy to the payloads and the amount of energy required to meet the $0.02 \mathrm{~kg} / \mathrm{hr}$ oxygen production rate, end to end operation to collect, separate, pressurize, and process $\mathrm{CO}_{2}$ into $\mathrm{O}_{2}$ is not possible. Therefore, the MARVIN instrument will be designed to operate in one of four different primary modes during ground checkout, the cruise to Mars, and on the surface of Mars. Because of the features and configuration options designed into MARVIN, each operating mode has different options that can be evaluated. The operating modes and options are:

1. Instrument health check

2. Atmosphere and Dust Measurement/Filtration: ADMF operation

- Filtration by HEPA filter

- Filtration by Electrostatic Precipitator

- Fitration by both

- No Filtration

3. Atmosphere and Dust Measurement,/Filtration, and $\mathrm{CO}_{2}$ Collection/Pressurization: ADMF and ICE CUBE operation

- With filtered atmosphere

- With unfiltered atmosphere

4. $\mathrm{O}_{2}$ Generation, Storage, and Purity Measurement: ICE CUBE and PROP operation

- Primary or backup SOE stack

- With filtered atmosphere

- With unfiltered atmosphere 
To minimize the power consumption rate and hardware mass for Mode 3 operation to collect, separate, and pressurization $\mathrm{CO}_{2}$, the Mars atmosphere is processed over 8 hours to collect the amount of $\mathrm{CO}_{2}$ needed to produce $0.02 \mathrm{~kg} / \mathrm{hr}$ of $\mathrm{O}_{2}$ for a minimum of one hour of operation. The $\mathrm{CO}_{2}$ collected by freezing is than allowed to warm up and self-pressurize the $\mathrm{CO}_{2}$ storage tank. Operation of Mode 4 to produce $\mathrm{O}_{2}$ can be performed on any subsequent Mars day as scheduling permits. The $\mathrm{CO}_{2}$ collection tank is designed to safely store the $\mathrm{CO}_{2}$ for as long as necessary (without power), but it is desired to operate Mode 4 within 7 days of $\mathrm{CO}_{2}$ collection. Figure 8 below depicts the estimated power profiles and total amount for MARVIN operating modes 2, 3, and 4. Both Mode 3 and 4 require a significant portion of the power supplied to all payloads, and therefore other instruments will most likely be shut off during these operations. Because it is important to collect as much information on the Mars atmosphere and dust content over the life of the mission, the low power consumption of Mode 2 will allow for its operation with other rover instruments, especially any Mars weather instruments that may be included on the Mars 2020 rover.

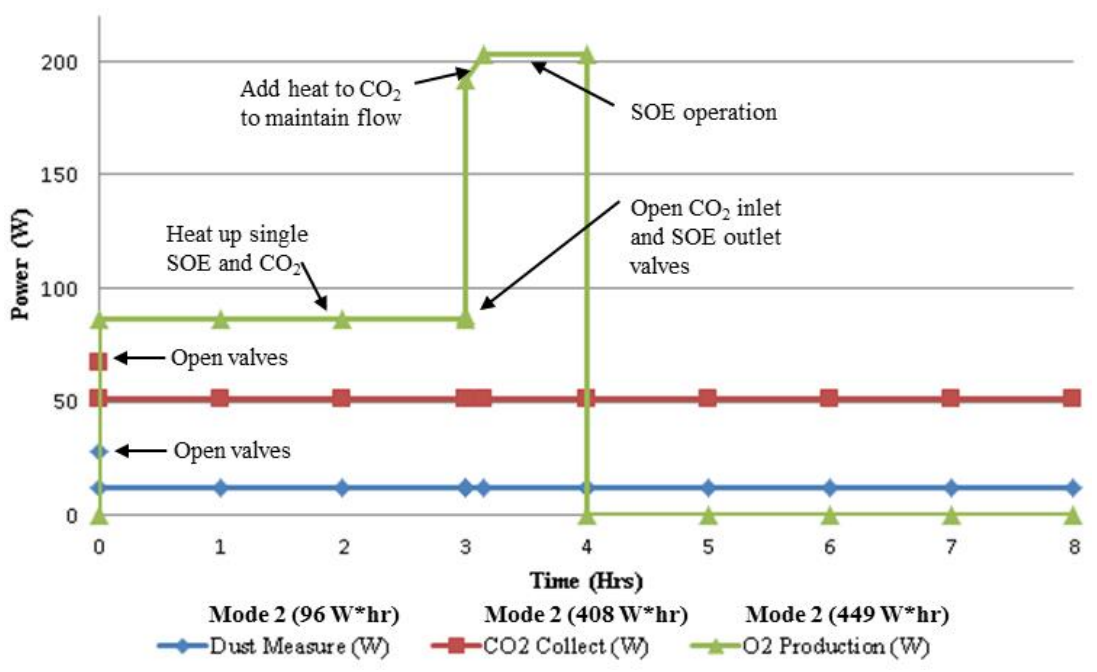

Figure 8. MARVIN Operation Modes and Power Profiles

\section{Past and Current Development and Hardware Heritage}

To reduce the cost and risk of the MARVIN instrument design, development, integration, test, and flight certification effort, the MARVIN team will utilize hardware, experience, and lessons learned from four past and current robotic mission flight instruments and proposals as depicted in Table 4. Three of these missions are ISRU related and the forth will minimize the cost and risk of integration and operation on the Mars surface.

Table 4. Extensive MARVIN Instrument Heritage

\begin{tabular}{|c|c|}
\hline Mission & everaged Heritage Experience \\
\hline $\begin{array}{l}2001 \text { Mars In situ propellant } \\
\text { production Precursor (MIP) }\end{array}$ & $\begin{array}{l}\text { The MIP flight experiment was built for the } 2001 \text { Mars Surveyor Lander mission with a similar goal as } \\
\text { MARVIN; to collect and store } \mathrm{CO}_{2} \text { from the Mars atmosphere and convert it into } \mathrm{O}_{2} \text { using a SOE cell. While } \\
\text { similar in size and mass to MARVIN (MIP was } 9.5 \mathrm{~kg} \text { and } 26 \times 24 \times 44 \mathrm{~cm} \text { ), power for MIP operations was } \\
\text { limited to } 15 \text { watts so the amount of } \mathrm{CO}_{2} \text { collected and processed into oxygen is less than } 1 / 500^{\text {th }} \text { of the } \\
\text { production rate of MARVIN. }\end{array}$ \\
\hline $\begin{array}{l}2003 \text { Propulsive Utilization } \\
\text { of Mars Produced } \\
\text { Propellants (PUMPP) }\end{array}$ & $\begin{array}{l}\text { The PUMPP experiment was a larger Mars ISRU experiment ( } 30 \mathrm{~kg} \text { and } 45 \text { Watts of power) proposed for the } \\
\text { Mars } 2003 \text { Mars Surveyor mission which was cancelled in } 2001 \text {. Even though the proposal was not selected, the } \\
\text { design and technologies were matured by NASA and Lockheed Martin Astronautics for several years } \\
\text { demonstrating critical technologies and design lessons learned that will be incorporated into MARVIN }\end{array}$ \\
\hline $\begin{array}{l}2018 \text { Regolith and } \\
\text { Environment Science \& } \\
\text { Oxygen and Lunar Volatile } \\
\text { Extraction (RESOLVE) }\end{array}$ & $\begin{array}{l}\text { The RESOLVE instrument package is currently under development for the Resource Prospector Mission } \\
\text { scheduled for a launch in April } 2018 \text { to the Moon to search for and characterize water/ice and other volatiles } \\
\text { within the top } 1 \text { meter of the lunar regolith. MARVIN will leverage on-going RESOLVE avionics and software } \\
\text { development, design experience, and personnel to minimize the cost risk for the Mars } 2020 \text { mission }\end{array}$ \\
\hline $\begin{array}{l}2011 \text { Sample Analysis on } \\
\text { Mars (SAM) instrument }\end{array}$ & $\begin{array}{l}\text { Since the MARVIN instrument will encompass similar physical, power, data, thermal, and atmosphere sample } \\
\text { collection/exhaust interfaces with the Mars } 2020 \text { rover as the SAM instrument on the Curiosity rover, the } \\
\text { MARVIN team will utilize SAM experience and expertise to bypass instrument issues and minimize the cost and } \\
\text { risk of integration and operation on the Mars surface. }\end{array}$ \\
\hline
\end{tabular}

As described in the subsystem description sections above, besides hardware and operation lessons-learned and experience from flight projects, the MARVIN team will leverage heritage designs from past and on-going 
technology, subsystem, and system development activities. Figure 9 depicts the components associated with the three main MARVIN ISRU subsystems and their current TRL.
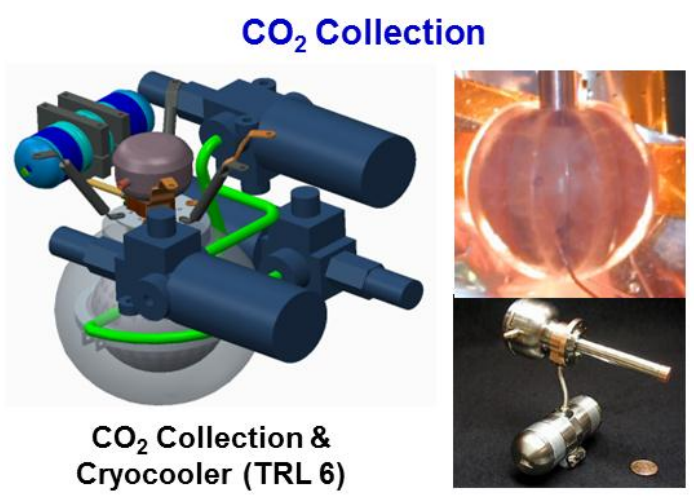

\section{Atmosphere/Dust Measurement}

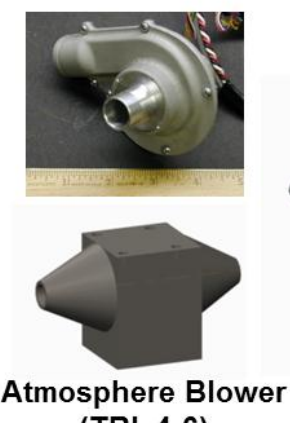

(TRL 4-6)

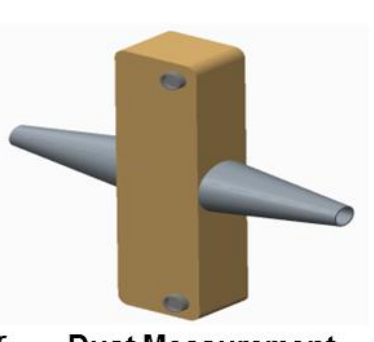

Dust Measurement (TRL 4)

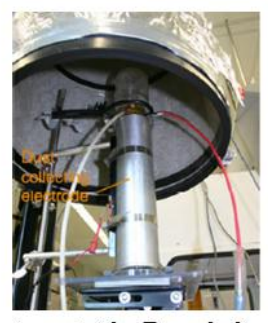

Electrostatic Precipitator

(TRL 3)
$\mathrm{O}_{2} \& \mathrm{O}_{2} \cdot \mathrm{CH}_{4}$ Production

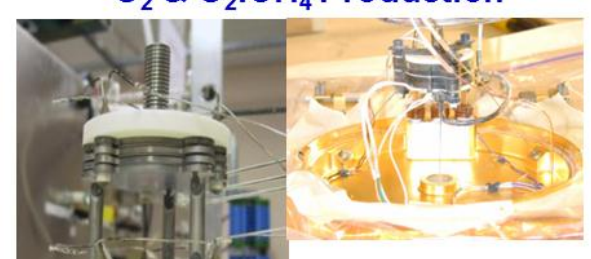

MIP 1 Cell SOE

(TRL 8)

Reactor (TRL 4)

Figure 9. Critical Hardware for MARVIN Instrument and Current TRL

\section{Compelling Nature of MARVIN Instrument}

The MARVIN instrument incorporates several advanced and unique technologies that will demonstrate critical ISRU capabilities that are extensible for future robotic and human exploration missions. The manner in which the technologies are incorporated into the MARVIN package also provides the ability to evaluate the performance and operation of several options for each MARVIN mode of operation. The compelling features associated with the MARVIN instrument technologies, configuration, and measurement capability are summarized in Table 5. A graphic of the MARVIN instrument package and components is depicted in Figure 10.

Table 4. Compelling Features of the MARVIN ISRU Investigation

\begin{tabular}{|c|l|l|}
\hline No. & \multicolumn{1}{|c|}{ Compelling Feature } & \multicolumn{1}{|c|}{ Benefit } \\
\hline 1 & $\begin{array}{l}\text { Unique 3-in-1 Solid Oxide Electrolysis (SOE) unit: } \mathrm{CO}_{2} \text { electrolysis, } \\
\text { Water electrolysis, \& Sabatier reactor are possible with same hardware }\end{array}$ & $\begin{array}{l}\text { Allows for simple system with multiple applications and } \\
\text { increased mission flexibility }\end{array}$ \\
\hline 2 & No Earth consumables or regents that have to be recycled & Unlimited operating life \\
\hline 3 & No operations requiring Earth delivered water & No planetary protection issues \\
\hline 4 & $\begin{array}{l}\mathrm{CO}_{2} \text { separation, collection, and pressurization that requires the } \\
\text { minimum of moving parts. }\end{array}$ & Minimizes risk for long term operation \\
\hline 5 & Filter bypass capability and redundant SOE units & $\begin{array}{l}\text { Allows for evaluation of impact of dust on ISRU } \\
\text { hardware }\end{array}$ \\
\hline 6 & $\begin{array}{l}\text { Incorporation of electrostatic precipitator filter } \\
\text { mitigation technique useful for other applications }\end{array}$ \\
\hline 7 & $\begin{array}{l}\text { Ability to simultaneously produce } \mathrm{O}_{2} \text { and methane }\left(\mathrm{CH}_{4}\right) \text { with simple } \\
\text { addition of hydrogen }(\mathrm{H} 2) \text { tank and control valves }\end{array}$ & $\begin{array}{l}\text { Increased mission data and applicability to future robotic } \\
\text { and human missions with ISRU }\end{array}$ \\
\hline
\end{tabular}

The environmental and hardware operation data collected by the MARVIN instrument will also be critical in reducing the risk of future missions. The measurements associated with the collection, separation, and processing of $\mathrm{CO}_{2}$ into $\mathrm{O}_{2}$ over the course of the mission are critical in satisfying Goal 1, demonstration technologies to enable 
production of oxygen from the Mars atmosphere. The measurement of dust particle sizes and amount in the Mars atmosphere throughout the Mars year is critical for satisfying Goal 2, characterizing atmospheric dust and morphology, but exposure of the blower and filter isolation valves to the entrained dust will also be instrumental in determining the impact of long term exposure of dust on hardware associated with Goal 1. The measurements of atmospheric pressure, temperature, and the size and amount of dust in gases coming into the MARVIN instrument will help understand atmospheric conditions around the rover. This information is essential to help further define Mars global circulation models (GCMs) and better understand the regional atmospheric dynamics associated with Goal 3, collect surface weather measurements to validate gloval atmospheric models. Diurnal pressure and temperature readings collected by MARVIN will be compared to data returned from other landers and to predictions from Mars GCMs. Seasonal changes will also be used to increase our understanding of longer term Martian climate variability and can be compared with data from past landers. The Dust Measurement Sensor in the ADMF will also provide an important and new measurement of the particle size distribution of dust in the Martian atmosphere, since previous dust measurements have been performed from orbit or on surface soils using imagery (scattering) or LIDAR; none have been done on actual airborne dust in the size ranges planned by MARVIN instrument. This will allow for a characterization of the airborne dust size distribution properties and how they change both diurnally and seasonally. This could have synergies with remote sensing experiments included in the rover science package, such as UV/VIS/NIR or Infra-red imagery.

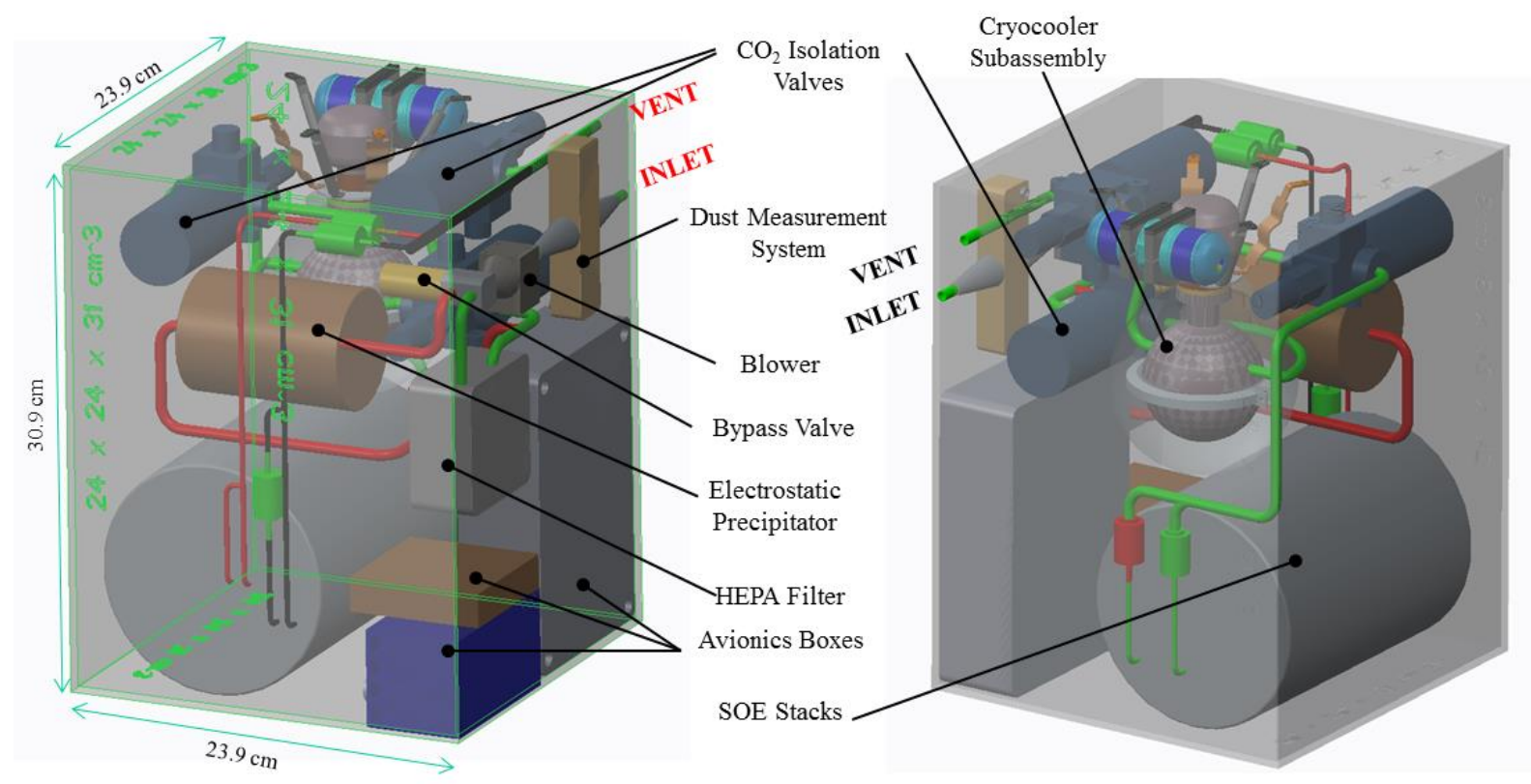

Figure 10. MARVIN Instrument Package and Major Components

\section{Acknowledgements}

The authors would thank and recognize the hard work and dedication of all the people that developed the MARVIN concept and proposal for the NASA Announcement of Opportunity for the Mars 2020 mission. In particular, the authors would like to recognize Bill Harris, Chris Madden, Nancy Munoz, Bart Smith, Sarah Walsh, and Steve Damico at JSC, Stan Starr, Curtis Ihlefeld, Tom Moss, and Robert Youngquist at KSC, and Todd Peters at Jacob.

\section{References}

1. Drake, Bret (editor), NASA/SP-2009-566-ADD, "Human Exploration of Mars Design Reference Architecture 5.0Addendum", July, 2009

2. G. B. Sanders, M. A. Interbartolo, W. E. Larson, e. al, "Early In-Situ Resource Utilizaiton (ISRU) Leading To Robust Sample Return and Human Exploration Missions", Mars Workshop - Lunar and Planetary Institute, Houston, TX. June, 2012.

3. "Analysis of Strategic Knowledge Gaps Associated with Potential Human Missions to the Martian System", Precursor Strategy Analysis Group (P-SAG), Final report June 30, 2012 
4. "Mars Science Goals, Objectives, Investigations, and Priorities: 2010", Mars Exploration Program Analysis Group (MEPAG), September 24, 2010

5. Ash, R.L., Dowler, W.L., Varsi, G., "Feasibility of Rocket Propellant Production on Mars", Acta Astronautica, Oct. 1978

6. Zubrin, R., Price, S., Mason, L., and Clark, L., "An End to End Demonstration of a Full Scale Mars Sample Return In-Situ Propellant Production Unit”, AIAA 95-2798, 31st AIAA Joint Propulsion Conference and Exhibit, July 10-12, 1995, San Diego, CA.

7. Sanders, J. B., "Integrated Propulsion and ISRU Propellant Production System for Mars Sample Return", AIA 95-2641, 31st Joint Propulsion Conference \& Exhibit, July 1995.

8. Wallace, R.A., Gamber, R.T., Clark, B.C., Sutter, B.M., "Low cost Mars Sample Return mission options", AIAA $34^{\text {th }}$ Aerospace Sciences Meeting and Exhibit, Reno, NV, Jan 15-18, 1996.

9. Clark, D. L., "In Situ Propellant Production On Mars: A Sabatier/Electrolysis Demonstration Plant", AIAA 972764, July, 1997

10. Rapp, D., "A Review of Mars ISPP Technology”, JPL Report D-15223, July, 1998

11. Wegeng, R., Sanders, G., "Microchemical and Thermal Systems for In Situ Resource Utilization", LPI Contribution No. 963, In Situ Resource Utilization (ISRU III) Technical Interchange Meeting, Feb 11-12, 1999, LMA Waterton Facility, Denver, CO.

12. Zubrin, R., Frankie, B. and Kito, T., "Mars In Situ Propellant Production Utilizing the Reverse Water Gas Shift”, LPI Contribution No. 963, In Situ Resource Utilization (ISRU III) Technical Interchange Meeting, Feb 11-12, 1999, LMA Waterton Facility, Denver, CO.

13. Frankie, B. and Zubrin, R., "Production of Higher Hydrocarbons Species on Mars", LPI Contribution No. 963, In Situ Resource Utilization (ISRU III) Technical Interchange Meeting, Feb 11-12, 1999, LMA Waterton Facility, Denver, CO.

14. Sanders, G. B., Trevathan, J. R., Kaplan, D. I., Peters, T. A., Baird, R. S., Cook, J. S., McClean, M., Pauly, K., "Development of In-Situ Consumable Production (ISCP) for Mars Robotic and Human Exploration at the NASA/Johnson Space Center", 00ICES-168, 30th International Conference on Environmental Systems (ICES), Toulouse, France, July, 2000.

15. Sanders, Gerald, "In-Situ Resource Utilization on Mars - Update from DRA 5.0 Study", AIAA-ASM-0799, Aerospace Science Meeting, Orlando Florida, Jan. 2010.

16. Muscatello, A.C. and Santiago-Maldonado, E., "Mars In Situ Resource Utilization Technology Evaluation," AIAA 2012-0360, 50th AIAA Aerospace Sciences Meeting, Nashville, Tennessee, January 2012.

17. Sanders, Gerald, "Mars In-Situ Resource Utilization (ISRU) sub-study for NASA Mars Collaborative Study Mars Sub-scale Precursor Mission Concepts", Phase I Report - Jan-April 2013.

18. Clark, D. L., Payne, K. S., and Trevathan, J. R., "Carbon Dioxide Collection and Purification System for Mars," AIAA 2001-4660, Space 2001, Albuquerque, New Mexico, August 2001.

19. Calle, C.I., P.J. Mackey, M.D. Hogue, M.R. Johansen, J.D. Kelley, J.R. Phillips, and J.S. Clements, "An electrostatic precipitator system for the Martian environment," Journal of Electrostatics, 71, 254-256 (2013)

20. Calle, C.I., M.R. Johansen, B.S. Williams, M.D. Hogue, P.J. Mackey, and J.S. Clements, "Martian atmospheric dust removal for ISRU intakes using electrostatic precipitation," Proceedings of the ASCE Earth and Space 2012 Conference, Pasadena, CA (2012)

21. Calle, C.I., S.M. Thompson, N.D. Cox, M.R. Johansen, B.S. Williams, M.D. Hogue, and J.S. Clements, "Electrostatic precipitation of dust in the Martian atmosphere: Implications for the utilization of resources during future manned exploration missions," Journal of Physics, 327, (2011)

22. Clements, J.S., S.M. Thompson, N.D. Cox, M.R. Johansen, B.S. Williams, M.D. Hogue, M.L. Lowder, and C.I. Calle, "Development of an electrostatic precipitator to remove Martian atmospheric dust from ISRU gas intakes during planetary exploration missions," Proceedings of the IEEE-IAS Conference, Orlando, FL (2011)

23. Malvern, Mastersizer Particle Size Analyzers, http://www.malvern.co/en/products/product-range/mastersizerrang/default.aspx

24. Microtrac, Total solutions in particle characterization, laser diffraction systems, http://www.microtrac.com/laser-diffraction-systems-for-particle-sizemeasurements/?gclid=CPSZk5Ko77sCFecRMwodpVEAqw

25. Sympatec GmbH, Laser Diffraction, http:///www.sympatec.com/EN/LaserDiffraction/LaserDiffraction.html

26. Stojanovic, Z., Markovic, S. (2012) 'Determination of Particle Size Distributions by Laser Diffraction', New Materials, no. 21, pp. 11-20 
27. Sanders, G. B. and, Peters, T. A., NASA/JSC, and Wegeng, R. S., TeGrotenhuis, W. E., Rassat, S. D., Brooks, K. P., and Stenkamp, S., DOE/PNNL, "Report On Development Of Micro Chemical/Thermal Systems For Mars ISRU-Based Missions", AIAA 2001-0939, 39th AIAA Aerospace Sciences Meeting, 8-11 January 2001

28. Sridhar, K., Gottmann, M., "Oxygen Generator System for Mars In-Situ Propellant Production Precursor Flight”, LPI Contribution No. 963, In Situ Resource Utilization (ISRU III) Technical Interchange Meeting, Feb 11-12, 1999, LMA Waterton Facility, Denver, CO.

29. Iacomini, C., and Benjamin, P., "Quantification of Methane Generation using a Solid Oxide Electrolyzer with an Electrode-based Sabatier Reactor for Oxygen Regeneration", SAE Int. J. Aerosp. 1 (1): 435-443, 2008.

30. Iacomini, C., Lund, L., and MacCallum, T., "Feasibility Demonstration of a Solid Oxide Electrolyzer with an Embedded Sabatier Reactor for Oxygen Regeneration", 37th International Conference on Environmental Systems, 2007-01-3158, 2007.

31. Iacomini, C. S., Powers, A., and Durant, T., "Design of a Stand-alone Solid Oxide Electrolysis Stack with Embedded Sabatier Reactors for 100\% Oxygen Regeneration", 2009-01-2440, 39th International Conference on Environmental Systems, 2009.

32. Iacomini, C., "Demonstration of a Stand-alone Solid Oxide Electrolysis Stack with Embedded Sabatier Reactors for 100\% Oxygen Regeneration", 41st International Conference on Environmental Systems, AIAA 2011-5016, Portland, Oregon, 2011.

33. Iacomini, C., "Water Requirements and Exhaust Products of Solid Oxide Electrolysis Systems with Embedded Sabatier Reactors for 100\% Oxygen Regeneration", 41st International Conference on Environmental Systems, AIAA 2011-5034, Portland, Oregon, 2011.

34. Small Business Innovation Research (SBIR) Phase $1 \& 2$ for Solid Oxide Electrolysis-Embedded Sabatier Reactor (SOE-ESR), Contracts NNJ06JD56C and NNJ07JA12C, COTR: Fred Smith, frederick.d.smith@nasa.gov, 281.483.9232

35. SBIR Phase 3 for Solid Oxide Electrolysis-Embedded Sabatier Reactor (SOE-ESR) Contract NNJ10HC33P, COTR: Su Curley, Su.curley-1@nasa.gov, 281-244-5722

36. "Oxygen Sensor / o2 Sensor Range." Oxygen Sensor Range. N.p., n.d. Web. 27 Nov. 2013. $<$ http://sstsensing.com/Products/Gas-Sensors/Oxygen-Sensors/47>.

37. "Honeywell." Sensors. N.p., n.d. Web. 27 Nov. 2013. <http://sensing.honeywell.com/index.php?ci id=50173>.

38. "Sensors." Delphi Mini-Switching Oxygen. N.p., n.d. Web. 27 Nov. 2013. $<$ http://delphi.com/manufacturers/auto/sensors/engine-and-transmission/gasoline/mini-switching-oxygen/>. 